Provided for non-commercial research and education use. Not for reproduction, distribution or commercial use.

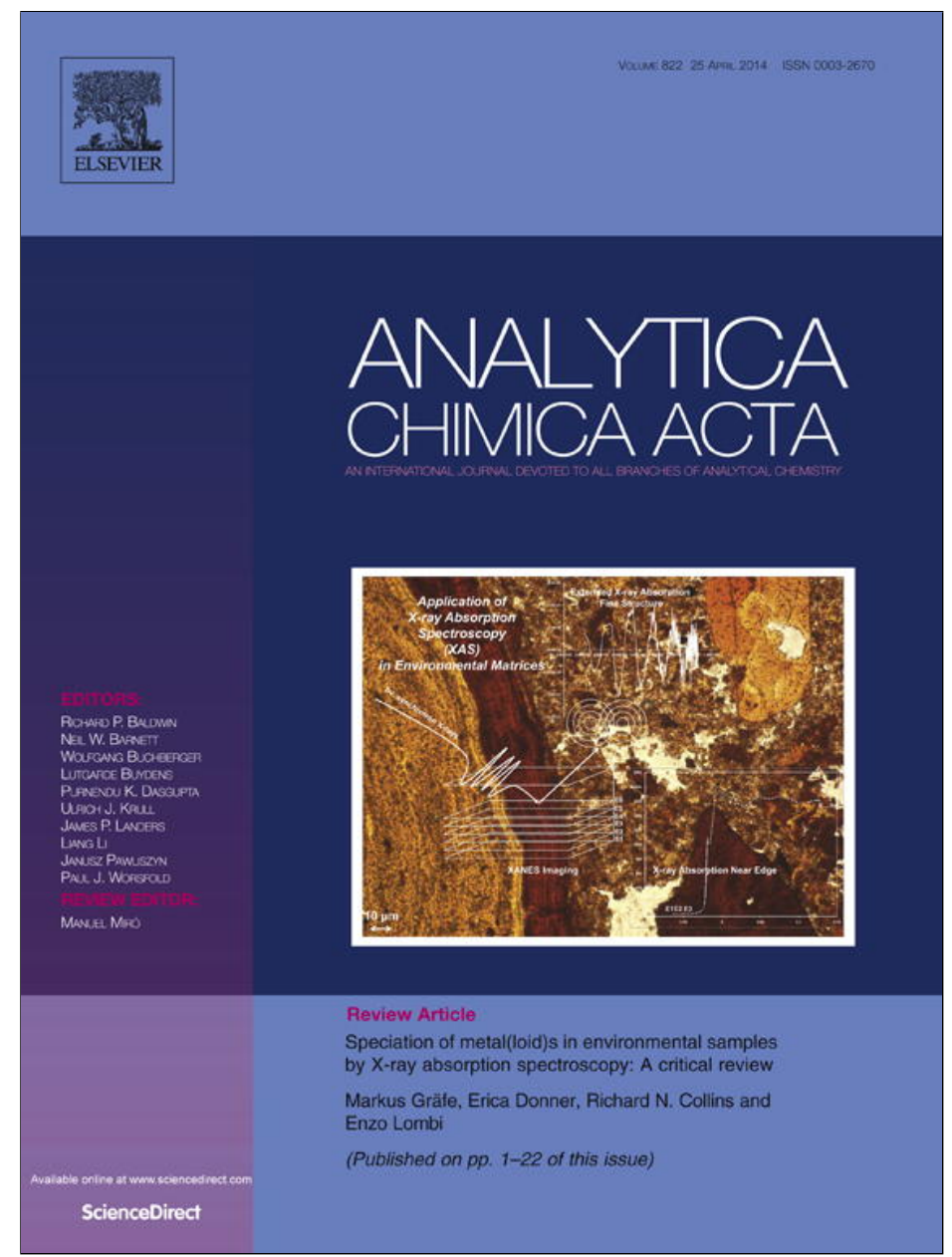

This article appeared in a journal published by Elsevier. The attached copy is furnished to the author for internal non-commercial research and education use, including for instruction at the authors institution and sharing with colleagues.

Other uses, including reproduction and distribution, or selling or licensing copies, or posting to personal, institutional or third party websites are prohibited.

In most cases authors are permitted to post their version of the article (e.g. in Word or Tex form) to their personal website or institutional repository. Authors requiring further information regarding Elsevier's archiving and manuscript policies are encouraged to visit:

http://www.elsevier.com/authorsrights 


\title{
Ultrasensitive electrochemical sensor for $p$-nitrophenyl organophosphates based on ordered mesoporous carbons at low potential without deoxygenization
}

\author{
Tingting Zhang ${ }^{\mathrm{a}, \mathrm{b}, 1}$, Lingxing Zeng ${ }^{\mathrm{c}, 1}$, Lei Han ${ }^{\mathrm{b}}$, Tie $\mathrm{Li}^{\mathrm{a}, *}$, Cheng Zheng ${ }^{\mathrm{c}}$, \\ Mingdeng $\mathrm{Wei}^{\mathrm{c}}$, Aihua Liu ${ }^{\mathrm{b}, *}$ \\ a College of Chemistry and Chemical Engineering, Ocean University of China, 238 Songling Road, Qingdao 266100, China \\ ${ }^{\mathrm{b}}$ Laboratory for Biosensing, Qingdao Institute of Bioenergy \& Bioprocess Technology, and Key Laboratory of Bioenergy, Chinese Academy of Sciences, 189 \\ Songling Road, Qingdao 266101, China \\ ${ }^{\mathrm{c}}$ Institute of Advanced Energy Materials, Fuzhou University, Fuzhou, Fujian 350002, China
}

\section{H I G H L I G H T S}

- Novel electrochemical sensor for $p$ nitrophenyl organophosphates based on ordered mesoporous carbons.

- Ultrasensitive detection of $p$-nitrophenyl organophosphates at $-0.085 \mathrm{~V}$.

- Direct detection of $p$-nitrophenyl OPs without deoxygenization.

\section{A R T I C L E I N F O}

\section{Article history:}

Received 21 January 2014

Received in revised form 13 March 2014

Accepted 17 March 2014

Available online 20 March 2014

\section{Keywords:}

Electrochemical sensor

p-Nitrophenyl organophosphates

Ordered mesoporous carbons

Voltammetric detection

\section{G R A P H I C A L A B S T R A C T}
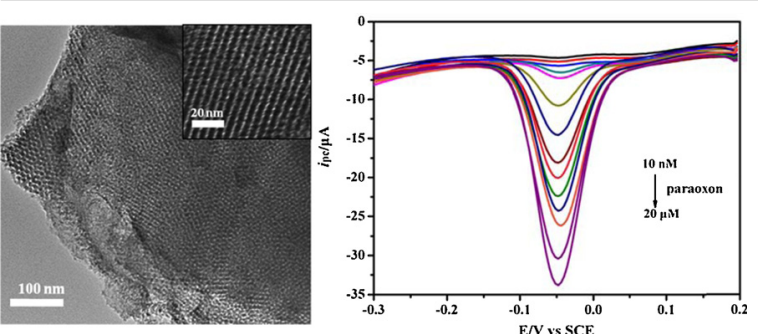

\begin{abstract}
A B S T R A C T
p-Nitrophenyl organophosphates (OPs) including paraoxon, parathion and methyl parathion, etc, are highly poisonous OPs, for which sensitive and rapid detection method is most needed. In this work, an ultrasensitive electrochemical sensor for the determination of $p$-nitrophenyl OPs was developed based on ordered mesoporous carbons (OMCs) modified glassy carbon electrode (GCE) (OMCs/GCE). The electrochemical behavior and reaction mechanism of $p$-nitrophenyl OPs at OMCs/GCE was elaborated by taking paraoxon as an example. Experimental conditions such as buffer $\mathrm{pH}$, preconcentration potential and time were optimized. By using differential pulse voltammetry, the current response of the sensor at $-0.085 \mathrm{~V}$ was linear with concentration within $0.01-1.00 \mu \mathrm{M}$ and $1.00-20 \mu \mathrm{M}$ paraoxon. Similar linear ranges of $0.015-0.5 \mu \mathrm{M}$ and $0.5-10 \mu \mathrm{M}$ were found for parathion, and $0.01-0.5 \mu \mathrm{M}$ and $0.5-10 \mu \mathrm{M}$ for methyl parathion. The low limits of detection were evaluated to be $1.9 \mathrm{nM}$ for paraoxon, $3.4 \mathrm{nM}$ for parathion and $2.1 \mathrm{nM}$ for methyl parathion $(S / N=3)$. Common interfering species had no interference to the detection of $p$-nitrophenyl OPs. The sensor can be applicable to real samples measurement. Therefore, a simple, sensitive, reproducible and cost-effective electrochemical sensor was proposed for the fast direct determination of trace $p$-nitrophenyl OPs at low potential without deoxygenization.
\end{abstract}

(c) 2014 Elsevier B.V. All rights reserved.

\footnotetext{
* Corresponding authors. Tel.: +86 532 80662758; fax: +8653280662778.

E-mail addresses: litie@ouc.edu.cn (T. Li), liuah@qibebt.ac.cn (A. Liu).

1 These two authors contributed equally to this work.
}

\section{Introduction}

Since the World Health Organization prohibited the use of organochlorine pesticides due to their serious bioaccumulation and persistence in the environment, the organophosphates (OPs) 
have become among the most widely used pesticides for pest control in agriculture [1,2]. OPs are also possibly used as chemical warfare agents in chemical war and terrorism $[3,4]$. There are many different kinds of OPs including paraoxon, parathion, dimethoate, phoxim, and so on [5-7]. The chemical structures of some common OPs are listed in Scheme 1. Although OPs are highly effective in pest control, degradable easily and less accumulative in living body, they are readily absorbed through skin and respiratory tract to risk the health of human and animals [8-10]. Generally, OPs are classified into high-, medium- and low-toxicity according to their hazardous levels [2,11]. Among them, $p$-nitrophenyl OPs including paraoxon, parathion and methyl parathion, etc., belong to highly poisonous OPs, and thereinto, paraoxon has the highest toxicity [2]. It is worth mentioning that parathion could convert into paraoxon through a series of photolysis and metabolic oxidation processes [8,12-14]. So it is highly desirable to develop rapid and sensitive approach to detect trace $p$-nitrophenyl OPs. It is wellknown that OPs are neurotoxic, which are readily to combine with acetylcholine esterase (AChE) to form phosphorus acylation cholinesterase immediately after the OPs are absorbed into the body, which makes the AChE lose the function of catalyzing the hydrolysis of acetylcholine, and lead to the massive accumulation of cholinergic neurotransmitter and bring about severe nerve function disorder [9,15-17]. Additionally, OPs may cause negative effect on the visual system, sensory function, cognitive function, and respiratory dysfunction which result in severe health problems and even death in both animals and humans $[15,18,19]$. Biosensors based on the inhibition of AChE have been widely developed for the detection of OPs. However, this method just can provide the total quantity of OPs. In addition, such inhibition-based biosensors involved a multiple-step operation involving time-consuming incubation and reactivation/regeneration processes. Thus, it is important and necessary to explore accurate, sensitive, rapid and portable methods to facilitate the detection of trace OPs.

Currently, several conventional detection techniques such as HPLC [20], GC/MS [21], capillary electrophoresis [22], flow injection analysis [23] and spectrophotomety [24] have been used in measuring the OPs in environment and food. The major disadvantages of these methods are laborous, expensive, and require trained personnel, which may not be suitable for on-site detection. Nowadays, electrochemical methods are more attractive for on-site monitoring of OPs because of their high sensitivity, good stability, minimal space and low-cost [25-29]. However, to the best of authors' knowledge, a nitrogen saturation condition is needed for most OPs detection based on electrochmical sensors $[8,9,12,13,18,19,22,30]$. Moreover, it is inconvenient for on-site measurement with deoxygenization.

In recent years, nano-scale materials have been widely used in the fabrication of electrochemical sensors to enhance the detection sensitivity [28,31-38]. The self-supported ordered mesoporous carbons (OMCs) structure was first reported by Ryoo and his coworkers in 1999, who employed the ordered aluminosilicate MCM48 as a hard template [39]. Due to their outstanding physicochemical properties including high surface areas, periodically arranged mono-dispersed mesopore space, tunable pore sizes, alternative pore shapes, uniform nanosized frameworks and abundant compositions [39], OMCs has aroused great interest in the past decade and has been widely used in sensor, energy storage, bioreactor and catalysis [40]. The merits such as fast electron transfer, high thermal stability and excellent electrocatalytic activity enable the OMCs to be a promising nanostructure for electrode modification. We used the OMCs modified glassy carbon electrode (GCE) (OMCs/GCE) for the simultaneous voltammetric detection of nitrophenol isomers [41] and determination of acidity coefficients $\left(\mathrm{p} K_{\mathrm{a}}\right)$ of phenol derivatives [42].<smiles>CCOP(=O)(OCC)Oc1ccc([N+](=O)[O-])cc1</smiles>

paraoxon<smiles>CCOP(=S)(OCC)Oc1ccc([N+](=O)[O-])cc1</smiles>

parathion<smiles>COP(=S)(OC)Oc1ccc([N+](=O)[O-])cc1</smiles>

methyl parathion<smiles>COP(=S)(OC)Oc1ccc([N+](=O)[O-])c(C)c1</smiles>

fenitrothion<smiles>C=P(OCC)(OCC)ON=C(N)c1ccccc1</smiles>

phoxim<smiles>COP(=O)(OC)Oc1nc(Cl)c(Cl)cc1Cl</smiles><smiles>C=P(OC)(OC)SCC(=O)NC</smiles>

chlorpyrifos 
In this paper, OMCs/GCE was prepared to investigate the response of $p$-nitrophenyl OPs. Paraoxon was chosen as the model to study the electrochemical behavior and reaction mechanism of $p$-nitrophenyl OPs at OMCs/GCE by cyclic voltammetry. The optimal conditions for $p$-nitrophenyl OPs detection were established. A simple, sensitive, reproducible and cost-effective sensor was proposed for the rapid direct detection of trace $p$-nitrophenyl OP pesticides at $-0.085 \mathrm{~V}$ without deoxygenization. Considering that the preparation of OMCs/GCE was simple without additional inclusion of functional materials, and the sensor is stable, therefore, the proposed approach is feasible for the detection of real samples.

\section{Materials and methods}

\subsection{Chemicals and reagents}

Nafion (perfluorinated ion-exchange resin, $5 \mathrm{wt} \%$ solution in a mixture of lower aliphatic alcohols and water) was purchased from Aldrich Corporation, from which the $0.05 \mathrm{wt} \%$ nafion was obtained. Paraoxon, parathion, methyl parathion and other OP pesticides were purchased from Sinopharm Chemical Reagent Corporation and used without further purification. The $20 \mathrm{mM}$ stock OP solutions were prepared with methanol and water (1:5) and stored in the darkness to avoid sunlight. The OPs solutions in low concentration should be prepared immediately before use. OP pesticides are highly toxic, which should be handled in the fume hood. Direct contact, inhalation or ingestion should be avoided by taking appropriate security precautions. Phosphate buffer saline (PBS, $0.1 \mathrm{M}$ ) was used as the supporting electrolyte. All other chemicals were commercially available and were of the highest grade and all solutions were prepared with ultrapure water. OMCs was synthesized according to our published paper [41].

\subsection{Preparation of OMCs modified electrode}

The preparation procedure can be found in our published paper [41]. In brief, the bare GCE (3 $\mathrm{mm}$ in diameter) was polished successively with 0.3 and $0.05 \mu \mathrm{m}$ alumina slurry and sonicated. Nafion-OMCs composite was prepared by dispersing $2.0 \mathrm{mg}$ OMCs powder into $1.0 \mathrm{~mL}$ nafion (0.05 wt\%) and sonicated. The GCE was coated with $10 \mu \mathrm{L}$ of the composite and dried under the room temperature $\left(\sim 23^{\circ} \mathrm{C}\right)$. Followed $4.0 \mu \mathrm{L}$ of nafion $(0.05 \mathrm{wt} \%)$ was syringed onto the surface of the modified electrode.

\subsection{Apparatus and methods}

Transmission electron micrograph (TEM) was taken on a F20 STWIN instrument (FEI, USA). The electrochemical measurements were performed on $\mathrm{CHI}$ 660D electrochemical workstation (Chenhua Co., Shanghai, China) with a conventional threeelectrode system comprising bare GCE or modified GCE as working electrode, platinum wire as auxiliary electrode and saturated calomel electrode (SCE) as reference electrode, respectively. All potentials in this paper were recorded versus SCE. All measurements were performed at room temperature $\left(\sim 23^{\circ} \mathrm{C}\right)$.

\section{Results and discussion}

\subsection{Characherization of the synthetized OMCs}

OMCs were synthesized according to our previous paper [41]. Fig. 1 shows the typical TEM image of OMCs. Well-ordered mesoporous pores with an average pore diameter of approximately $3.9 \mathrm{~nm}$ can be clearly observed without carbon deposition on the external surface. As depicted in the inset of Fig. 1, the mesoporous

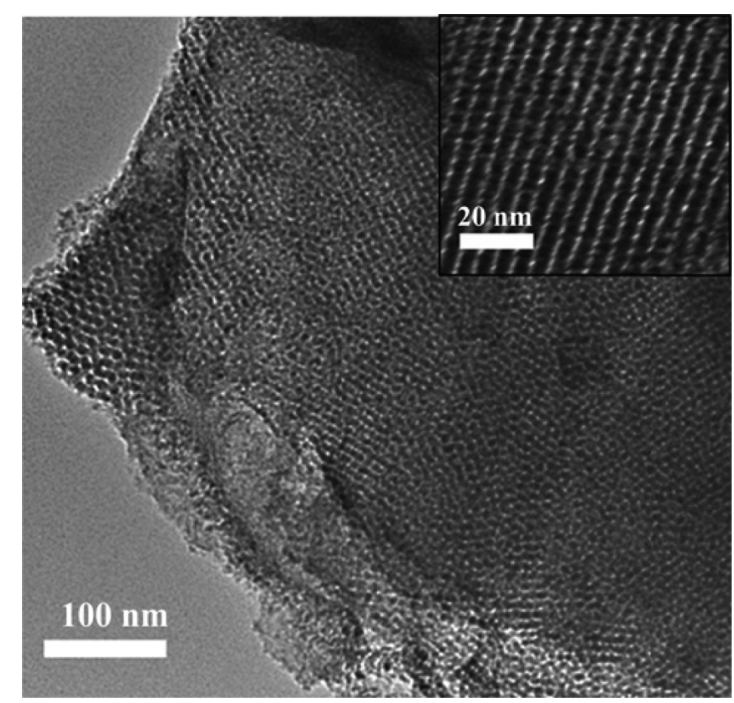

Fig. 1. TEM image of the prepared OMCs. Inset, the amplied image.

carbon possessed regular arrangement of two-dimensional mesoporous channels. This high surface area and large pore volume of mesoporous carbon may act as catalyst support. Additional catalytic functions are possibly introduced by incorporation of active sites on the walls or by deposition of active sites on the inner surface of the carbon.

\subsection{Electrochemical behavior of paraoxon at OMCs/GCE}

The electrochemical behavior of paraoxon at OMCs/GCE and bare GCE was systematically studied by cyclic voltammetry (CV). Within the potential window ranging from -0.8 to $0.2 \mathrm{~V}$, there was no peak appeared except for the reduction of oxygen at $-0.4 \mathrm{~V}$ approximately at OMCs/GCE in the absence of parapxon (Fig. 2, curve b). At $\mathrm{OMCs} / \mathrm{GCE}, 10 \mu \mathrm{M}$ paraoxon exhibited a clear nitryl- $\mathrm{NO}_{2}$ reduction peak at $-0.593 \mathrm{~V}$ and the reduction of oxygen (around $-0.4 \mathrm{~V}$ ) had no influence on this peak (Fig. 2, curve d). Further, a pair of well-defined redox peaks appeared at approximately $-0.1 \mathrm{~V}$ at OMCs/GCE (Fig. 2, curve d). In $10 \mu \mathrm{M}$ paraoxon, at bare GCE, two separate redox peaks appeared, i.e., a broad

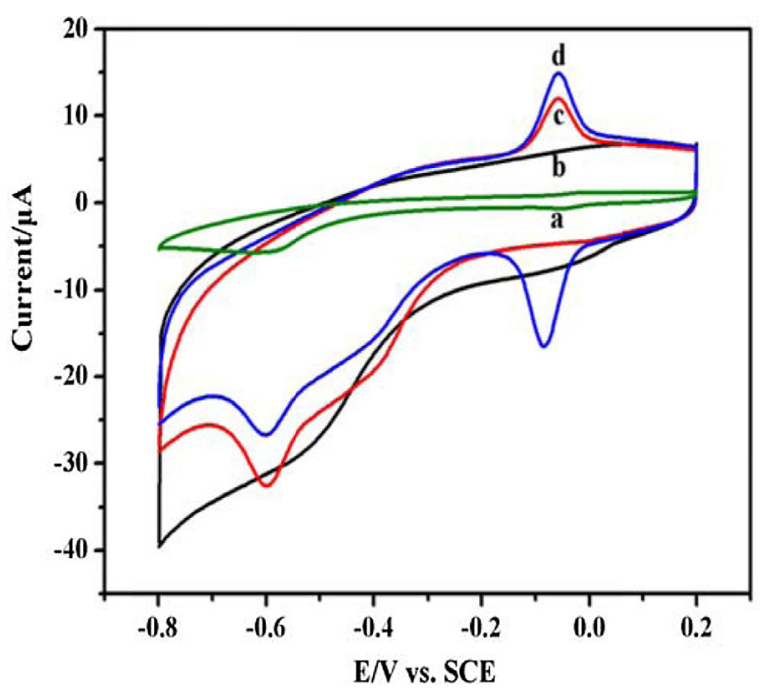

Fig. 2. Cyclic voltammograms (CVs) of bare GCE in $10 \mu \mathrm{M}$ paraoxon buffered with PBS (pH 6.0) (a) and OMCs/GCE in PBS (pH 6.0) buffer (b). Continuous CV measurement of OMCs/GCE in $10 \mu \mathrm{M}$ paraoxon buffered with $\mathrm{PBS}(\mathrm{pH} 6.0)$ at (c) the 1 st cycle and (d) the 5 th cycle. Scan rate, $50 \mathrm{mV} \mathrm{s}^{-1}$. 
reduction peak appeared at $-0.62 \mathrm{~V}$ responsible for the combination of the reduction peak of nitryl group and oxygen, and a pair of weak redox peaks at approximately $-0.1 \mathrm{~V}$, which corresponded to the reversible conversion between hydroxamino $(-\mathrm{NHOH})$ and nitroso group ( $-\mathrm{NO}$ ) electrochemically reduced from nitryl (Fig. 2, curve a). Further, compared with bare GCE, the OMCs/GCE had the obviously large background current and signifcant signal current in $10 \mu \mathrm{M}$ paraoxon, suggesting the modified electrode exhibited good electrocatalytic activity and preconcentration function towards paraoxon. The plenty of edge plane-like defects and oxygencontaining functional groups such as carbonyl on the surface of OMCs would provide lots of favorable sites for electron transfer. And the large surface area, arranged mono-dispersed mesopore channels and the silicon dioxide in wall of holes were remained during the synthesis process could perform intense preconcentration function towards paraoxon. To illustrate the electrochemical mechanism, continuous $\mathrm{CV}$ responses of $10 \mu \mathrm{M}$ paraoxon at OMCs/ GCE were measured for five cycles. During the first cycle, only one broad reduction peak appeared at $-0.593 \mathrm{~V}$ in the sweep, which was related to the irreversible reduction of nitryl, while in the anodic sweep a poignant oxidation peaks emerged at $-0.046 \mathrm{~V}$ (Fig. 2, curve c). In the 5 th cycle, the CV became stable. Further, in addition to the reduction peak of nitryl, a new reduction peak appeared at $-0.085 \mathrm{~V}$ in the cathodic sweep (Fig. 2, curve d), which corresponded to the oxidation peak at $-0.046 \mathrm{~V}$. Comparing the first cycle with the 5 th cycle, it is obvious that the reversible redox peak couples increased at the expense of the decrease of the reduction peak of nitryl. So it is apparent that the peak couples are derived from the intermediate products of nitryl group reduction, which may become the basis for paraoxon detection. According to the early literature, the nitryl is irreversibly reduced to hydroxamino along with a four-electron and four-proton transfer process (Scheme 2, reaction 1). The reversible redox peaks are attributed to a two-electron and two-proton transfer process (Scheme 2, reaction 2 ), which is the reversible conversion between hydroxamino and nitroso group. The reaction mechanism can also be applied at OMCs/GCE. In the following sections, the reduction peak at $-0.085 \mathrm{~V}$ was tested to optimize the experimental conditions such as buffer $\mathrm{pH}$, preconcentration potential and time to improve the detection sensitivity and evaluate the analytical performance for the detection of OPs at OMCs/GCE.

\subsection{Optimization of the experimental conditions}

\subsubsection{Effect of buffer $p H$}

The experimental conditions have significant influence on the detection sensitivity of OPs. As protons participate in this reaction at OMCs/GCE, the acidity of PBS buffer has a remarkable effect on the electrochemical behavior of paraoxon. As buffer $\mathrm{pH}$ was increased from 4.0 to 8.0, the CV response of the three peaks showed up similar trend (Supplementary material, Fig. S1A). Here the cathodic peak current $\left(i_{\mathrm{pc}}\right)$ of the reversible peaks was studied in this paper. At first, the current response climbed up and reached to the maximum at $\mathrm{pH} 6.0$, then declined significantly along with the increase of buffer pH. Here the cases for $\mathrm{pH} 5.5$ and 6.5 were also compared. The result showed that the best peak shapes and high sensitivities were obtained at $\mathrm{pH} 6.0$ (Supplementary material, Fig. S1B), so PBS buffer with $\mathrm{pH} 6.0$ was selected in this study. Meanwhile, with the increase of $\mathrm{pH}$, the cathodic peak potential $\left(E_{\mathrm{pc}}\right)$ shifted negatively and showed linear relationship with $\mathrm{pH}$ (Supplementary material, Fig. S1C). The linear regression equation was $E_{\mathrm{pc}}($ paraoxon $)=-0.053 \mathrm{pH}+0.220$ with $R=0.9931$. According to the following formulum:

$\frac{\mathrm{d} E_{\mathrm{p}}}{\mathrm{dpH}}=-2.303 \frac{m \mathrm{RT}}{n \mathrm{~F}}$

where $m$ and $n$ refer to the transferring number of protons and electrons, respectively. The value of $m / n$ in this reaction was calculated to be 1.0 approximately, indicating that the transferring number of protons and electrons were equal, which was in good accordance with the literatures reported $[9,10,25,30]$.

\subsubsection{Effect of preconcentration potential and preconcentration time}

The effects of preconcentration potential and preconcentration time on the current response are illustrated in Fig. 3. As preconcentration potential was altered from 0 to $-1.2 \mathrm{~V}$, the current response climbed up first and reached to the maximum at $-0.6 \mathrm{~V}$, and then remained almost unchanged (Fig. $3 \mathrm{~A}$ ). Thus, the optimum preconcentration potential should be $-0.6 \mathrm{~V}$ for sensitive analytical of paraoxon. The optimization of preconcentration time is demonstrated in Fig. 3B. The peak current increased with the time and a plateau was reached at about $100 \mathrm{~s}$. So the optimum preconcentration potential and preconcentration time were $-0.6 \mathrm{~V}$ and $100 \mathrm{~s}$, respectively.

\subsubsection{Effect of scan rate}

The effect of scan rate on CV responses of paraoxon at OMCs/ GCE was studied (Supplementary material, Fig. S2). Both the oxidation peaks and reduction peaks enhanced with the increase of scan rate, while the peak potential remained almost unchanged (Supporting Information, Fig. S2A). Both the anodic and cathodic peak currents were linearly proportional to the square root of scan rate in the range of $20-300 \mathrm{mV} \mathrm{s}^{-1}$ (Supplementary material, Fig. S2B), suggesting that the redox of paraoxon at OMCs/GCE was a diffusion-controlled process.

\subsection{Analytical performance for the detection of OPs at OMCS/GCE}

Under the above optimal experimental conditions, OMCs/GCE was used to detect paraoxon by differential pulse voltammetry (DPV). The DPV responses were recorded in PBS ( $\mathrm{pH}$ 6.0) containing different concentration of paraoxon at OMCs/GCE (Fig. 4). Along with the increase of the concentration of the paraoxon, the currents enhanced gradually and the peak became sharper (Fig. 4A). The $i_{\mathrm{pc}}$ at $-0.085 \mathrm{~V}$ was linear with the concentration of paraoxon ranging from 0.01 to $1.00 \mu \mathrm{M}$ and $1.00-20 \mu \mathrm{M}$ (Fig. 4B). The linear regression equations were $i_{\mathrm{pc}}$ (paraoxon) $=9.988$ Conc. +0.075 at low concentration with a correlation coefficient $(R)$ of 0.9991 and $i_{\mathrm{pc}}$ (paraoxon) $=0.9732$

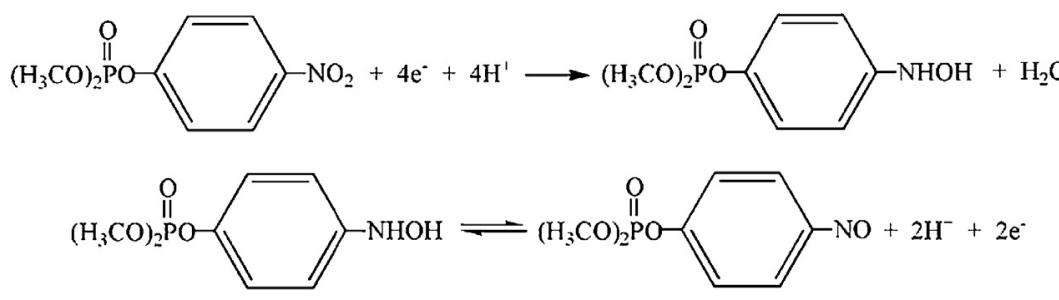

Scheme 2. The electrochemical reaction mechanism at OMCs/GCE. 

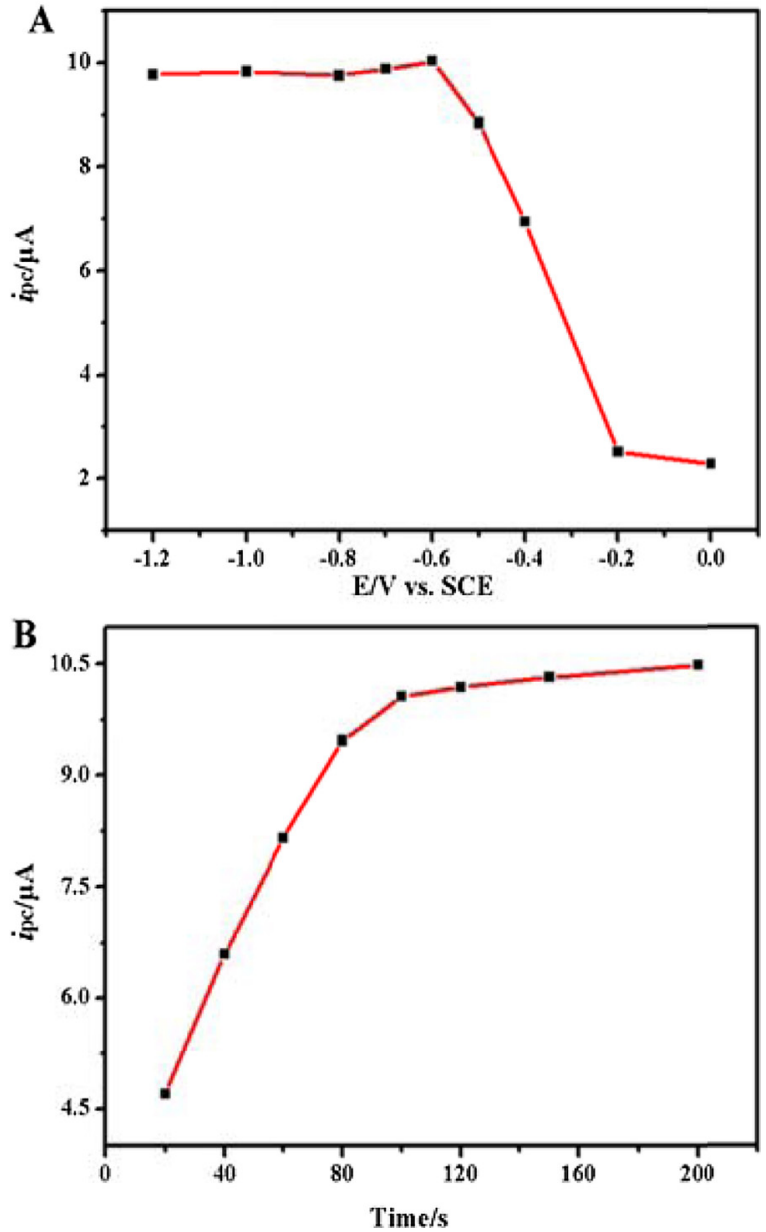

Fig. 3. (A) Effect of preconcentration potential on CV response. (B) Effect of preconcentration time on CV response. CVs were measured in $0.1 \mathrm{M}$ PBS ( $\mathrm{pH} 6.0$ ) buffer containing $10 \mu \mathrm{M}$ paraoxon at OMCs/GCE. Scan rate, $50 \mathrm{mV} \mathrm{s}^{-1}$.

Conc. +9.312 at high concentration with $R$ of 0.9958 . The limit of detection (LOD) of paraoxon was evaluated to be $1.9 \mathrm{nM}(S / N=3)$. Some other kinds of OPs were also measured by DPV at OMCs/GCE and the results are summarized in Table 1. As can be seen, parathion and methyl parathion which contain p-nitrophenyl in structure can also be detected sensitively. The LODs of parathion and methyl parathion were $3.4 \mathrm{nM}$ and $2.1 \mathrm{nM}$, respectively (Table 1). Because the current signal was originating from $p$-nitrophenyl portion of the OPs, it is reasonable that the OPs without $p$-nitrophenyl such as phoxim chlorpyrifos and dimethoate did not have any responses at OMCs/GCE (Table 1). In the context, different modified electrodes were reported for detection of $p$-nitrophenyl OPs. For example, dynamic detection ranges were reported to be 1-60 $\mu \mathrm{M}$ methyl parathion for carbon paste electrode (CPE) [25], 0.02-0.38 $\mu \mathrm{M}$ methyl parathion for zirconia nanoparticles modified gold electrode
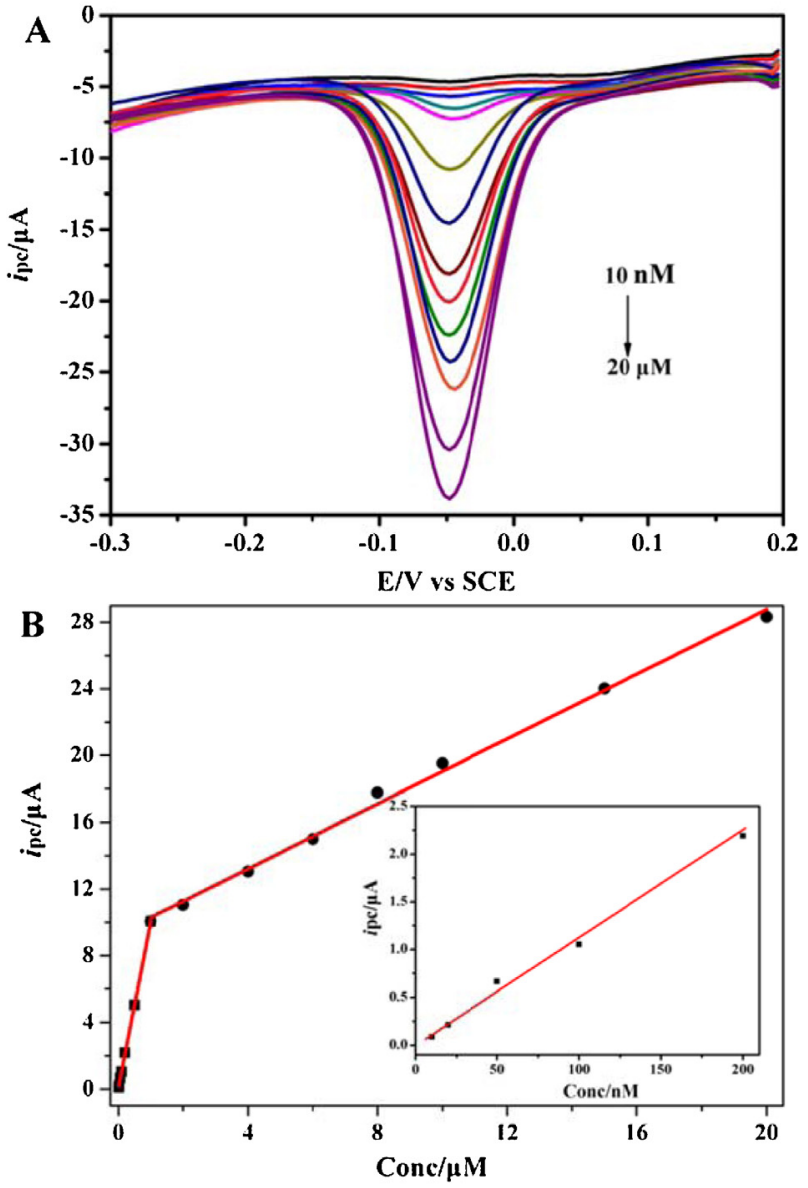

Fig. 4. (A) Differential pulse voltammograms (DPVs) of paraoxon varying concentration at OMCs/GCE in 0.1 M PBS (pH 6.0). (B) The calibration curve for paraoxon. Inset, the enlarged portion of the current as a function of paraoxon concentration within $10-200 \mathrm{nM}$. Before measurement, the electrode was preconcentrated at $-0.6 \mathrm{~V}$ for $100 \mathrm{~s}$. DPV conditions: equilibration time, $2 \mathrm{~s}$; potential amplitude, $50 \mathrm{mV}$; pulse period: $0.5 \mathrm{~s}$; step height, $4 \mathrm{mV}$; frequency, $60 \mathrm{~Hz}$.

[30], 0.2-1.00 $\mu \mathrm{M}$ methyl parathion for silver nanoparticles modified GCE [43], and $0.2-8.0 \mu \mathrm{M}$ parathion for multiwalled carbon nanotube modified CPE [44]. Further, our method is also sensitive than organophosphorus hydrolase (OPH)-based OP biosensor [45], and bacteria-displaying OPH-based OP optical sensor [46] or OP electrochemical biosensor [47]. Obviously, the OMCs/GCE in this study showed wider dynamic detection ranges and corresponding lower detection limits. Further, in our case, the preparation of OMCs/GCE was simple without additional inclusion of functional materials. The edge plane-like defective site and oxygen-containing functional groups such as carbonyl existing on the surface of OMCs can provide a great deal of favorable sites to transmit electrons of electroactive substances. In addition, to date, almost all of the other papers on OPs detection need a nitrogen

Table 1

The linear ranges and the limits of detection of some OPs using the proposed sensor.

\begin{tabular}{lll}
\hline OPs & Linear range $(\mu \mathrm{M})$ \\
\hline Paraoxon & $0.01-1.00$ and $1.00-20$ \\
Parathion & $0.015-0.5$ and $0.5-10$ \\
Methyl parathion & $0.01-0.5$ and $0.5-10$ & 1.9 \\
Phoxim & ND & 3.4 \\
Chlorpyrifos & ND & 2.1 \\
Dimethoate & ND & - \\
\hline
\end{tabular}

ND, not detectable. DPV conditions: equilibration time, $2 \mathrm{~s}$; potential amplitude, $50 \mathrm{mV}$; pulse period: $0.5 \mathrm{~s}$; step height, $4 \mathrm{mV}$; frequency, $60 \mathrm{~Hz}$. Before measurement, the electrode was preconcentrated at $-0.6 \mathrm{~V}$ for $100 \mathrm{~s}$. 
saturation condition, which means that the existence of oxygen will affect the $p$-nitrophenyl OPs detection $[5,6,8,13,25,30,39,44]$. In this work, the detection of $p$-nitrophenyl OPs with or without nitrogen saturation condition has been tested, and it was proved that the oxygen reduction on the OMCs/GCE had no influence on the detection of $p$-nitrophenyl OPs, which is a great advantage over other similar methods reported so far. The existence of oxygen in buffer just had effect on the reduction of nitryl which have similar reaction potential. In this paper, the reduction peak (at $-0.085 \mathrm{~V}$ ) of the intermediate product was investigated to detect $p$-nitrophenyl, so a nitrogen saturation condition was not needed.

\subsection{Interference study}

The possible interference from some inorganic ions and organic compounds on the detection of OPs at OMCs/GCE was studied. The $i_{\mathrm{pc}}$ of OPs in the presence of other species was measured for three times. If the $i_{\mathrm{pc}}$ change was within $5 \%$ in the presence of other species, it would be considered that there was no interference on the detection. A great number of cations such as $\mathrm{Na}^{+}, \mathrm{K}^{+}, \mathrm{Al}^{3+}, \mathrm{Cu}^{2+}$, $\mathrm{Ca}^{2+}, \mathrm{NH}_{4}^{+}, \mathrm{Zn}^{2+}, \mathrm{Mg}^{2+}$ and anions such as $\mathrm{NO}_{3}{ }^{-}, \mathrm{Br}^{-}, \mathrm{Cl}^{-}, \mathrm{HCO}_{3}{ }^{-}$, $\mathrm{SO}_{4}{ }^{2-}, \mathrm{H}_{2} \mathrm{PO}_{4}^{-}$and $\mathrm{Ac}^{-}$were tested. 100 -fold excess of these ions did not affect the determination of OPs. Similarly, organic compounds including phenol, nitrophenols, benzene, cresol, chlorophenol, salicylic acid, and other interference substances were tested in the same way and also had no effect on the determination of $p$-nitrophenyl OPs.

\subsection{Stability of $O M C s / G C E$}

A consecutive CV measurement was carried out to test the operational stability of OMCs/GCE. The peak currents retained over $96 \%$ of their initial values and without obvious potential shift after continuous 100 circles (Supplementary material, Fig. S3), indicating that the modified electrode exhibited good operational stability. The long-term stability of the modified electrode was also evaluated in $10 \mu \mathrm{M}$ paraoxon in $0.1 \mathrm{M}$ PBS (pH 6.0) buffer at OMCs/GCE. The current response was measured every two days and the modified electrode was stored in $4{ }^{\circ} \mathrm{C}$ refrigerator when it was not in use. During the first three weeks, there was no apparent decrease of the current response. After that, the current response began to decrease gradually. However, one month later the current signals still remained $75 \%$ initial response (Supplementary material, Fig. S4). The decrease in response from the 4th week on may be caused by the partial fall off of OMCs from the electrode surface.

\subsection{Real samples measurements}

To study the applicability of the sensor, real samples such as tap water, seawater and sewage were measured. The sample solutions were filtered through a $0.22 \mu \mathrm{m}$ membrane, and the filtrate was collected. Before measurement, the ionic strength and $\mathrm{pH}$ of the real samples should be adjusted according to the preparation procedure of PBS buffer by adding suitable amount of $\mathrm{KCl}, \mathrm{NaCl}$, $\mathrm{K}_{2} \mathrm{HPO}_{4}$ and $\mathrm{NaH}_{2} \mathrm{PO}_{4}$. The recovery of this method was investigated by standard addition method. Each sample was measured six times. The recoveries are between $95 \%$ and $105 \%$, so the proposed method was feasible for the detection of real samples (Supplementary material, Table S1).

\section{Conclusions}

In summary, an electrochemical sensor based on OMCs/GCE for the ultrasenstive determination of $p$-nitrophenyl OP pesticides was developed. The electrochemical behavior and reaction mechanism of paraoxon at OMCs/GCE were discussed. By using DPV technique, the OMCs/GCE can be used to detect $p$-nitrophenyl OPs including paraoxon, parathion and methyl parathion. Therefore, a simple, sensitive, reproducible and cost-effective sensor was proposed for the fast direct measurement of trace $p$-nitrophenyl OPs without deoxygenization. The preparation of OMCs/GCE is simple without additional inclusion of functional materials, and the sensor is stable and feasible for the detection of real samples.

\section{Acknowledgements}

This work was financially supported by National Natural Science Foundation of China (Nos. 91227116, 21173049 and 21275152) and the Hundred-Talent-Project (No. KSCX2-YW-BR7), Chinese Academy of Sciences.

\section{Appendix A. Supplementary data}

Supplementary data associated with this article can be found, in the online version, at http://dx.doi.org/10.1016/j.aca.2013.12.001.

\section{References}

[1] N. Senanayake, L. Karalliedde, Neurotoxic effects of organohosphorus insecticides, New England Journal of Medicine 316 (1987) 761-763.

[2] M.A. Brown, K.A. Brix, Review of health consequences from high-, intermediate- and low-level exposure to organophosphorus nerve agents, Journal of Applied Toxicology 18 (1998) 393-408.

[3] N.A. Minton, V.S. Murray, A review of organophosphate poisoning, Medical Toxicology and Adverse Drug Experience 3 (1988) 350-375.

[4] A.-F. Ngomsika, A. Beeb, M. Drayea, G. Cotea, V. Cabuilb, Magnetic nano- an microparticles for metal removal and environmental applications: a review, Comptes Rendus Chimie 8 (2005) 963-970.

[5] Y. Qu, H. Min, Y. Wei, F. Xiao, G. Shi, X. Li, L. Jin, Au-TiO $2 /$ chit modified sensor for electrochemical detection of trace organophosphates insecticides, Talanta 76 (2008) 758-762.

[6] H.E. Tome, U. Gombert, T. Breton, Electrochemical stripping analysis of methyl parathion (MPT) using carbon fiber microelectrodes (CFME) modified withcombinations of poly-NiTSPc and Nafion films, Sensors and Actuators B 124 (2007) 368-375.

[7] J. Kassa, H. Králové, Review of oximes in the antidotal treatment of poisoning by organophosphorus nerve agents, Clinical Toxicology 40 (2002) 803-816.

[8] M.R. Majidi, K.A. Zeynali, M. Nazarpur, Determination of fenitrothion in river water and commercial formulations by adsorptive stripping voltammetry with a carbon ceramic electrode, Journal of AOAC International 92 (2009) 548-554.

[9] C. Li, C. Wang, C. Wang, S. Hu, Development of a parathion sensor based on molecularly imprinted nano- $\mathrm{TiO}_{2}$ self-assembled film electrode, Sensors and Actuators B 117 (2006) 166-171.

[10] J. Gong, X. Miao, T. Zhou, L. Zhang, An enzymeless organophosphate pesticide sensor using Au nanoparticle-decorated graphene hybrid nanosheet as solidphase extraction, Talanta 85 (2011) 1344-1349.

[11] J. Bajgar, Organophosphates nerve agent poisoning: mechanism of action diagnosis, prophylaxis, and treatment, Advances in Clinical Chemistry (2004) $151-216$.

[12] C. Li, C. Wang, Y. Ma, W. Bao, S. Hu, A novel amperometric sensor and chromatographic detector for determination of parathion, Analytical and Bioanalytical Chemistry 381 (2005) 1049-1055.

[13] T. Alizadeh, Comparison of different methodologies for integration of molecularly imprinted polymer and electrochemical transducer in order to develop a paraoxon voltammetric sensor, Thin Solid Films 518 (2010) 6099-6106.

[14] S.O. Pehkonen, Q. Zhang, The degradation of organophosphorus pesticides in natural waters: a critical review, Critical Reviews in Environmental Science and Technology 32 (2002) 17-72.

[15] V.A. Pedrosa, D. Miwa, S.A.S. Machado, L.A. Avaca, On the utilization of boron doped diamond electrode as a sensor for parathion and as an anode for electrochemical combustion of parathion, Electroanalysis 18 (2006) 1590-1597.

[16] S. Karami-Mohajeri, M. Abdollahi, Toxic influence of organophosphate, carbamate, and organochlorine pesticides on cellular metabolism of lipids, proteins, and carbohydrates: a systematic review, Human and Experimenta Toxicology 30 (2011) 1119-1140.

[17] D. Collins, A review of alternatives to organophosphorus compounds for the control of storage mites, Journal of Stored Products Research 42 (2006) 395-426.

[18] L. Zeng, Q. Li, D. Tang, G. Chen, M. Wei, Metal platinum-wrapped mesoporous carbon for sensitive electrochemical immunosensing based on cyclodextrin functionalized graphene nanosheets, Electrochimica Acta 68 (2012) $158-165$.

[19] M. Wang, Z. Li, Nano-composite $\mathrm{ZrO}_{2} / \mathrm{Au}$ film electrode for voltammetric detection of parathion, Sensors and Actuators B 133 (2008) 607-612. 
[20] C.G. Pinto, J.L.W. Pavh, B.M. Cordem, Cloud point preconcentration and highperformance liquid chromatographic determination of organophosphorus pesticides with dual electrochemical detection, Analytical Chemistry 67 (1995) 2012-2606.

[21] R. Bravo, W.J. Driskell, R.D. Whitehead Jr., L.L. Needham, D.B. Barr, Quantitation of dialkyl phosphate metabolites of organophosphate pesticides in human urine using GC-MS-MS with isotopic internal standards, Journal of Analytical Toxicology 26 (2002) 245-252.

[22] Q. Chen, Y. Fung, Capillary electrophoresis with immobilized quantum dot fluorescence detection for rapid determination of organophosphorus pesticides in vegetables, Electrophoresis 31 (2010) 3107-3114.

[23] M. Shi, J. Xu, S. Zhang, B. Liu, J. Kong, A mediator-free screen-printed amperometric biosensor for screening of organophosphorus pesticides with flow-injection analysis (FIA) system, Talanta 68 (2006) 1089-1095.

[24] S.B. Mathew, A.K. Pillai, V.K. Gupta, A rapid spectrophotometric assay of some organophosphorus pesticide residues in vegetable samples, Spectrochimica Acta Part A 67 (2007) 1430-1442.

[25] G. Liu, Y. Lin, Electrochemical stripping analysis of organophosphate pesticides and nerve agents, Electrochemistry Communications 7 (2005) 339-343.

[26] D.A. Roston, P.T. Kissinger, Series dual-electrode detector for liquid chromatography/electrochemistry, Analytical Chemistry 54 (1982) 429-434.

[27] H. Parham, N. Rahbar, Square wave voltammetric determination of methyl parathion using $\mathrm{ZrO}_{2}$-nanoparticles modified carbon paste electrode, Journal of Hazardous Materials 177 (2010) 1077-1084.

[28] D. Du, X. Ye, J. Zhang, Y. Zeng, H. Tu, A. Zhang, D. Liu, Stripping voltammetric analysis of organophosphate pesticides based on solid-phase extraction at zirconia nanoparticles modified electrode, Electrochemistry Communications 10 (2008) 686-690.

[29] J. Gong, L. Wang, D. Song, X. Zhu, L. Zhang, Stripping voltammetric analysis of organophosphate pesticides using Ni/Al layered double hydroxides as solidphase extraction, Biosensors and Bioelectronics 25 (2009) 493-496.

[30] G. Liu, Y. Lin, Electrochemical sensor for organophosphate pesticides and nerve agents using zirconia nanoparticles as selective sorbents, Analytical Chemistry 77 (2005) 5894-5901.

[31] M. Zhang, W. Gorski, Electrochemical sensing platform based on the carbon nanotubes/redox mediators-biopolymer system, Journal of the American Chemical Society 127 (2005) 2058-2059.

[32] J. Wang, Electrochemical glucose biosensors, Chemical Reviews 108 (2008) $814-825$.

[33] A. Liu, H. Geng, C. Xu, H. Qiu, A three-dimensional hierarchical nanoporous PdCu alloy for enhanced electrocatalysis and biosensing, Analytica Chimica Acta 703 (2011) 172-178

[34] L. Li, B. Liang, J. Shi, F. Li, M. Mascini, A. Liu, A selective and sensitive D-xylose electrochemical biosensor based on xylose dehydrogenase displayed on the surface of bacteria and multi-walled carbon nanotubes modified electrode, Biosensors and Bioelectronics 33 (2012) 100-105.

[35] C. Hu, D. Yang, Z. Wang, L. Yu, J. Zhang, N. Jia, Improved EIS performance of an electrochemical cytosensor using three-dimensional architecture Au@BSA as sensing layer, Analytical Chemistry 85 (2013) 5200-5206.

[36] A. Liu, Towards development of chemosensors and biosensors with metaloxide-based nanowires or nanotubes, Biosensors and Bioelectronics 24 (2008) 167-177.

[37] A. Liu, M.D. Wei, I. Honma, H. Zhou, Biosensing properties of titanate-nanotube films: selective detection of dopamine in the presence of ascorbate and uric acid, Advanced Functional Materials 16 (2006) 371-376.

[38] A. Liu, G. Abbineni, C. Mao, Nanocomposite films layer-by-layer assembled from genetically engineered filamentous viruses and gold nanoparticles: nanoarchitecture- and humidity-tunable surface plasmon resonance spectra, Advanced Materials 21 (2009) 1001-1005.

[39] C. Liang, Z. Li, S. Dai, Mesoporous carbon materials: synthesis and modification, Angewandte Chemie-International Edition 47 (2008) 3696-3717.

[40] J.C. Ndamanisha, L. Guo, Ordered mesoporous carbon for electrochemical sensing: a review, Analytica Chimica Acta 747 (2012) 19-28.

[41] T. Zhang, Q. Lang, D. Yang, L. Li, L. Zeng, C. Zheng, T. Li, M. Wei, A. Liu, Simultaneous voltammetric determination of nitrophenol isomers at ordered mesoporous carbon modified electrode, Electrochimica Acta 106 (2013) 127-134.

[42] T. Zhang, Q. Lang, L. Zeng, T. Li, M. Wei, A. Liu, Substituent effect on the oxidation peak potentials of phenol derivatives at ordered mesoporous carbons modified electrode and its application in determination of acidity coefficients ( $\mathrm{p} K_{2}$ ), Electrochimica Acta 115 (2014) 283-289.

[43] A. Kumaravel, M. Chandrasekaran, A novel nanosilver/nafion composite electrode for electrochemical sensing of methyl parathion and parathion, Journal of Electroanalytical Chemistry 638 (2010) 231-235.

[44] D. Du, M. Wang J. Zhang J. Cai, H. Tu, A. Zhang, Application of multiwalled carbon nanotubes for solid-phase extraction of organophosphate pesticide, Electrochemistry Communications 10 (2008) 85-89.

[45] R.P. Deo, J. Wang, I. Block, A. Mulchandani, K.A. Joshi, M. Trojanowicz, F. Scholz, W. Chen, Y.H. Lin, Determination of organophosphate pesticides at a carbon nanotube/organophosphorus hydrolase electrochemical biosensor, Analytica Chimica Acta 530 (2005) 185-189.

[46] X. Tang, B. Liang, T. Yi, G. Manco, I. Palchetti, A. Liu, Cell surface display of organophosphorus hydrolase for sensitive spectrophotometric detection of $p$ nitrophenol substituted organophosphates, Enzyme and Microbial Technology 55 (2014) 107-112.

[47] P. Mulchandani, W. Chen, A. Mulchandani, J. Wang, L. Chen, Amperometric microbial biosensor for direct determination of organophosphate pesticides using recombinant microorganism with surface expressed organophosphorus hydrolase, Biosensors and Bioelectronics 16 (2001) 433-437. 